\title{
Experimental and multiscale numerical investigation of wear mechanism and cutting performance of polycrystalline diamond tools in micro-end milling of titanium alloy Ti-6Al-4V
}

\author{
Jinxuan Bai ${ }^{1,2 *}$, Qingshun Bai ${ }^{*}$, Zhen Tong ${ }^{3}$ \\ 1 School of Mechanical and Electrical Engineering, Harbin Institute of Technology, Harbin 150001, China \\ 2 School of Mechanical Engineering, Purdue University, West Lafayette 47907, US \\ 3 Centre for Precision Technologies, University of Huddersfield, Huddersfield HD1 3DH, UK \\ *Corresponding author: jinxuanbai@hit.edu.cn, qshbai@ hit.edu.cn
}

\begin{abstract}
The present study reports on experiments and numerical simulations carried out to determine the wear and cutting performance of different polycrystalline diamond (PCD) tools in micro-end milling titanium alloy. The influence of tool geometrical parameters on wear resistance and machined surface precision was discussed. Furthermore, subsurface microstructure alteration was employed as an important index for evaluating the cutting performance of PCD tools. A dislocation dynamics-based multiscale framework, which is capable of promulgating the potential mechanism of above alteration, was adopted to quantitatively predict the evolution behavior of subsurface damages layer during micro-cutting process. The results demonstrated that the tool nose, flank and rake wear were of major wear forms and inappropriate tool structural changes can further accelerate tool failure. A PCD tool with rake angle of $5^{\circ}$, clearance angle of $15^{\circ}$, tool cutting edge radius of $20 \mu \mathrm{m}$ and PCD granularity of $10 \mu \mathrm{m}$ has highest cutting performance among the tested tools. Using this cutting tool, a surface roughness of Ra $=75 \mathrm{~nm}$ better than most previously reported value on titanium alloy Ti-6Al-4V was achieved. A mass of subsurface damages consisted of discrete dislocation configuration, parallel glide lines and persistent slip bands were found after machining. Particularly, small tool cutting edge radius, large rake as well as clearance angle contributed to reducing defects quantity and decreasing the thickness of subsurface damages layer.
\end{abstract}

Keywords: PCD tool; geometrical parameters; wear mechanism; cutting performance; subsurface microstructure

\section{Introduction}

Titanium alloys are one of the essential supporting materials in aerospace, automotive and biomedical fields because of the attractive physical and mechanical performance. However, Ducobu et al. [1] indicated that the poor thermal conductivity coupled with high chemical reactivity led them to be hard-to-machine materials as well. Li et al. [2] asserted that polycrystalline diamond (PCD) has been widely applied as a kind of advanced preparation material in machining titanium alloy due to the excellent hardness. Amin et al. [3] found that sluggish tool wear behavior and approximately two times greater workpiece removal area per tool life can be obtained with PCD mills in comparison to tungsten carbide tools in machining titanium alloy. Similarly, Ding et al. [4] presented that the PCD tools also showed better application performances than polycrystalline cubic boron nitride tools due to higher abrasion wear and fracture resistance. Therefore, PCD micro-milling technology has been thought as a promising manufacturing method and widely applied in industry for the fabrication of high-quality components with surface precision in micro- and nano- range. However, Bai et al. [5] suggested that, in comparison to traditional processing way, the micro-milling mode has to suffer more severe machining conditions i.e. higher rotation speed and cutting temperature together with greater tribological interaction between tool-tip and workpiece substrate, which may adversely impact the performance for workpiece removal as well as finished surface and subsurface precision.

In micro-milling titanium alloy with PCD tools, Salesa et al. [6] indicated that reduced tool yield strength 
induced by high machining temperature in association with continuous impact pressure on tool surface can lead to the acceleration of tool wear. Being for the purpose of forecasting tool failure and prolonging tool life within a fundamental method, the effect of processing parameters on machining performance and surface topography has been the focus of attention and research. Li et al. [7] reported the experimental investigation of high-speed wet milling titanium alloy. Their results showed that cutting speed had a profound influence on the wear mechanism of PCD tools, which was mainly due to the premature breakage together with the synergistic interaction among adhesive and abrasive wear. Based on the results of PCD tools machining titanium alloy under different coolant pressures, Silva et al. [8] asserted that adhesion and attrition wear were dominant of tool failure. Abbasi et al. [9] presented an investigation of milling titanium alloy Ti-6Al-4V with $16 \mathrm{~mm}$ diameter PCD end-mills. Their experiments indicated that all of the evaluation parameters of tool failure and machined surface quality were depended upon the cutting depth and cutting velocity. Furthermore, according to the investigation on the evolution of cutting force, friction coefficient and anti-adhesion in turning titanium alloy, Su et al. [10] discussed the quality and performance of PCD tools with micro-groove cutting edge structure. Similarly, Li et al. [11] explored the effect of the preparation technology on the performance of PCD tools. However, although lots of studies were carried out to reveal the wear mechanism and cutting capability of PCD tool, the systematic experimental and theoretical analysis on the relationship between tool geometrical parameters and wear resistance, surface finish as well as subsurface damages microstructure are limited.

Recently, as the demand for surface accuracy, the assessment of machining quality of tools depends on more than the shape and feature of processed surface, Wang et al. [12] indicated that the characteristics and morphologies of components subsurface microstructure should be used to determine the dependability and durability of tool as well. Based on cutting titanium alloy experiments, Che-Haron et al. [13] asserted that a thin subsurface deformed layer was found vertically below finished surface, and the results indicated that the thickness of damages layer would continue to increase with the augment of tool wear. Noted that the experiments can reflect certain subsurface features qualitatively, but no experimental or numerical studies were ever employed to quantitatively investigate the effect of tool geometric construction on the nucleation and transmutation characteristics of subsurface defects microstructure. In comparison to atomic-scale simulation technology, dislocation dynamics (DD) technology allows for a better scalability of the overall solution in more complicated time and space scale range. Likewise, DD approach also offered a better perspective on workpiece substrate subsurface damage behaviors than continuum mechanism. In particular, according to DD technology, Bai et al. [14, 15] established a new multiscale coupling framework to present the mechanism of surface grain refining and subsurface damages evolution during orthogonal cutting titanium alloy Ti-6Al-4V. Corresponding experimental results indicated that the predications were in agreement with the experimental data very well, which demonstrated that the DD-based trans-scale model was an effective and accurate way of describing the response mechanism of subsurface damages microstructure to external tool geometrical changes.

Currently, insufficient experimental results and simulated data available on the structural characterisation of PCD micro-end milling cutter limited its industrial application. The objective of present study is to perform micro-processing titanium alloy experiments and multiscale simulations with various micro-mills to investigate the influence of tool intrinsic and extrinsic geometrical parameters on tool wear behavior together with machined surface and subsurface generation mechanism. Organization for the remainder of this work is consisted of the following key parts. Section 2 introduces the experimental procedure and multiscale machining framework. Tool wear, machined surface topography, finished surface roughness and subsurface microstructure alteration are presented and discussed in Section 3. Following in Section 4 is the summary of this manuscript with some main conclusions. 


\section{Experiments procedure and multiscale simulation model}

\subsection{Experimental setup}

The micro end-milling experiments were carried out on the self-developed miniature CNC milling machine tool. The image of the experimental setup and the schematic diagram of control system were shown in Fig.1. It owns three linear axes and two revolving axes. The maximum spindle speed reaches $8 \times 10^{4} \mathrm{rpm}$ and the repetition is $\pm 1 \mu \mathrm{m}$. The processed material used in present work was titanium alloy Ti-6Al-4V bulks with the size of $40 \mathrm{~mm}$ $\times 20 \mathrm{~mm} \times 20 \mathrm{~mm}$, which was bonded to a ground metal plate. Furthermore, different PCD brand-new tools were adopted in micro-milling experiments.

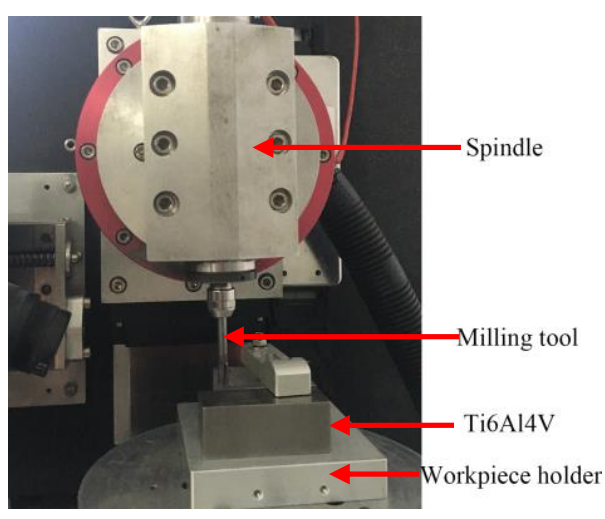

(a)

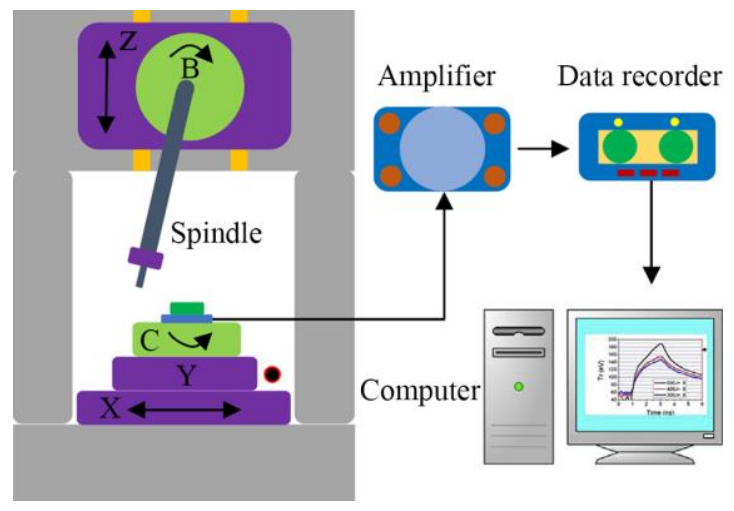

(b)

Figure 1. Miniature milling machine tool. (a) experimental setup. (b) schematic diagram of control system.

\subsection{Design of machining experiments}

All experiments were immersion slot milling in this work. For each group of experiments, the feed direction

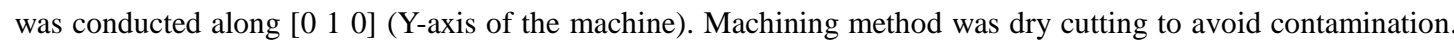
Consistent processing parameters were used in this experimental work. In addition, to reveal the influence of tool geometry on the wear and machining qualities, three controllable variables were performed, i.e. tool cutting edge radius $(\mu \mathrm{m})$, rake angle $\left({ }^{\circ}\right)$ and clearance angle $\left({ }^{\circ}\right)$. In addition, in order to obtain the dependence of PCD granularity, two different particle sizes were set for four mills. The specific tool parameters were shown in Table.1. In order to reveal the key influence factors and their interaction, a $3 \times 3 \times 3 \times 2$ mixed-level full machining conditions were carried out, which would conduct a more comprehensive assessment than previous literatures. Specially, to maximize the reduction of mismachining tolerance and inhibit the influence of machine tool vibration, every set of tests was repeated once.

\subsection{Evaluation for finished surfaces microstructure}

After cutting, the morphologies of end-mills were detected in a scanning electron microscope (SEM) fitted with x-ray energy dispersive spectrometry (EDS). Furthermore, for diversity assessment of cutting performance, ultra-depth three-dimensional microscopy and white light interferometer were used to acquire the finished surface topographic characteristic and the surface roughness of micro-grooves. Specially, for each micro-groove, the surface precisions in various locations were obtained along transverse direction, calculating the average value. 
Table 1. The milling parameters and responses in experiments.

\begin{tabular}{ccccccc}
\hline Test no. & $\begin{array}{c}\text { tool diameter } \\
(\mathrm{mm})\end{array}$ & $\begin{array}{c}\text { cutting edge radius } \\
(\mu \mathrm{m})\end{array}$ & $\begin{array}{c}\text { rake angle } \\
\left({ }^{\circ}\right)\end{array}$ & $\begin{array}{c}\text { clearance angle } \\
\left({ }^{\circ}\right)\end{array}$ & $\begin{array}{c}\text { granularity } \\
(\mu \mathrm{m})\end{array}$ & $\begin{array}{c}\text { surface roughness value } \\
(\mu \mathrm{m})\end{array}$ \\
\hline 1 & 4.5 & 20 & 5 & 15 & 10 & 0.075 \\
\hline 2 & 4.5 & 30 & 5 & 15 & 10 & 0.109 \\
\hline 3 & 4.5 & 40 & 5 & 15 & 10 & 0.135 \\
\hline 4 & 4.5 & 20 & 3 & 15 & 10 & 0.104 \\
\hline 5 & 4.5 & 20 & 1 & 15 & 10 & 0.091 \\
\hline 7 & 4.5 & 20 & 5 & 8 & 10 & 0.107 \\
\hline 8 & 4.5 & 20 & 5 & 5 & 25 & 0.165 \\
\hline 9 & 4.5 & 20 & 5 & 15 & 25 & 0.200 \\
\hline
\end{tabular}

\subsection{Multiscale assessment framework for subsurface damage}

A multiscale dislocation dynamics assessment framework for subsurface damages was proposed in Fig. 2, aiming at revealing the major effect mechanism of tool geometrical transformation on subsurface damages layer quantitatively and qualitatively. This model incorporated two different characteristic modules, discrete scale in nanometer level and continuum scale. For the former case, Bai et al. [16] performed a kind of DD model combing dislocation movement, pile-up, annihilation and spatial rearrangement to calculate the interaction effect between subsurface damages and lattice boundaries. In the second case, Huang et al. [17] developed new coupling model to transfer the plastic strain captured by discrete dislocation dynamic model to the finite element model as an eigen-strain, which can be used to get the stress and temperature distribution applied to individual defect in the processing of micromechanical structures. Specially, a series of dislocation motions, multiplication and close encounters have to remain under particular principles. Moreover, the position of Frank-Read (F-R) dislocation sources is based on stochastic distribution on the glide planes, which possess specific characteristic nucleation strength and time. Analogously, lots of stored obstacles also distribute randomly across slip system. According to Davoudi et al. [18], dislocations are permitted to move beyond original glide plane if their climb displacement is greater than the absolute value of Burgers vector. In particular, a series of improved constitutive laws are used to incorporate 3D defect characteristics into 2D model to further reinforce the interaction of subsurface defects. What is worth mentioning is that Benzerga et al. [19] indicated that above features not only act as potential obstacles and hinder subsequent defects, but may form new F-R dislocation sources. 


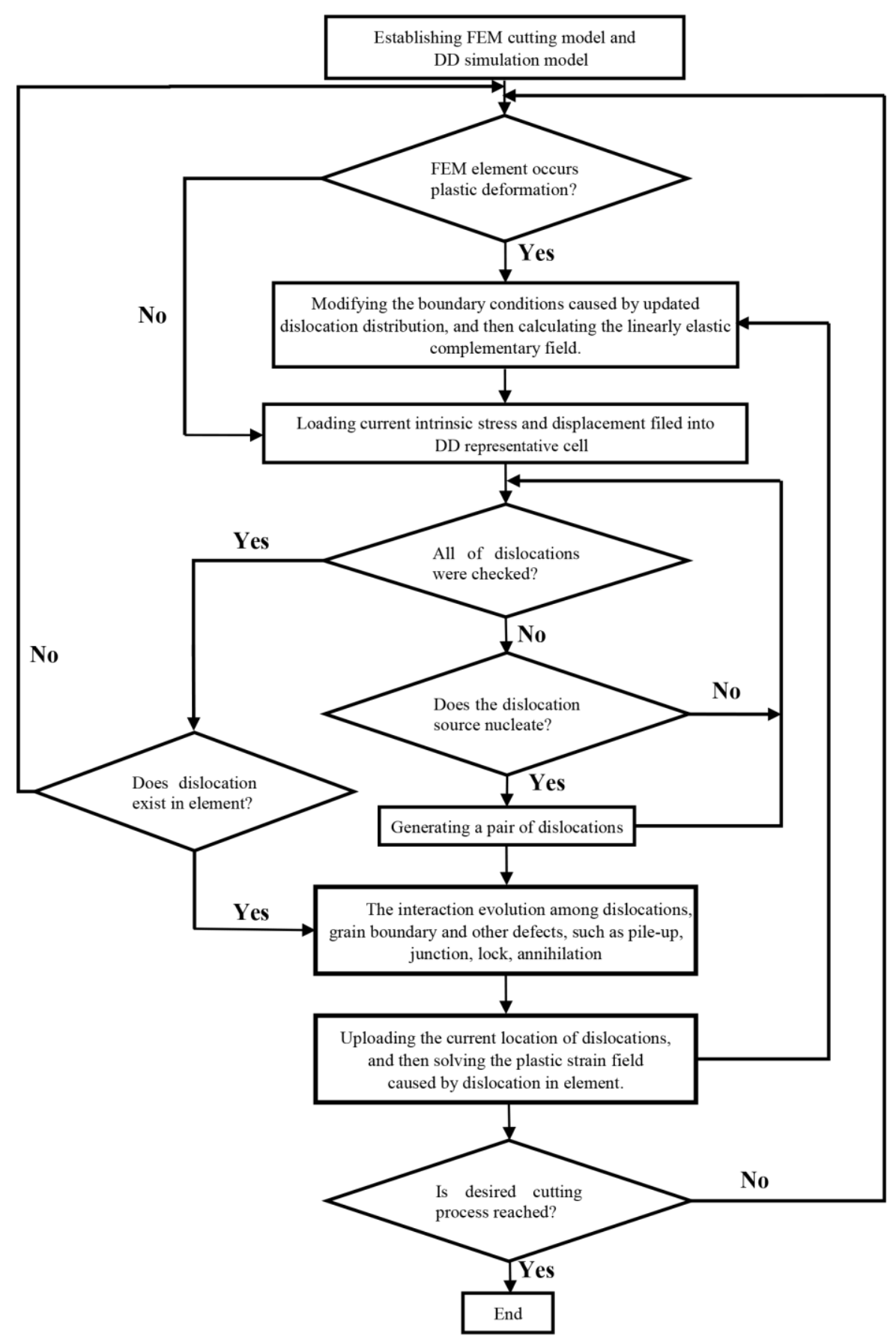

Figure 2. Multiscale discrete dislocation dynamics assessment framework for subsurface damages.

\section{Results and Discussion}

\subsection{Wear mechanism of machining tool}

Since the interaction between thermal and mechanical load in micro-cutting is more complicated than that in traditional processing mode, tool life expectancy raises a problem and peculiar tool geometries and materials have been devised to suppress tool wear. As flank wear can reflect the interactive features of tool flank surface and machined surface, the worn behaviors of tools' flank face after milling micro-grooves were depicted in Figure 3. The acquired SEM images indicated that various structural parameters of cutting tool would result in multifarious wear features. It can be seen that the main wear behavior consisted of abrasion and adhesion between flank surface 
and workpiece substrate. It always originated from a local region in the vicinity of tool nose into a big triangle area. In addition, on the basic of the images around tool cutting edge, a large area of titanium alloy was found to adhere to wore flank face. Tool abrasion and attrition process would take part of adhesion material away from PCD surface. However, as the adhesion layer eroded, exposed micro-end mills had to suffer more severely fracture failure.

The integrity of cutting edge seriously affects surface precision in a diamond milling operation. Therefore, the edge wear characteristic can be seen as a crucial factor that determines PCD tool life. By contrasting Fig. 3a-3c, chipping and fracture characteristics were found nearby tool nose. Although the notching of tool nose and the abrasion of flank face were main damage patterns, it is noteworthy that the wear rate of the former is gradual greater than the latter one associated with tool cutting edge radius augments. Actually, increscent cutting edge not only can accelerate the bluntness of tool nose, but raise the temperature in the vicinity of tool-tip. Combined with the low thermal conductivity of titanium alloy, above characteristics further induced the adhesion of workpiece material on tool flank surface. Furthermore, the cutting heat and discontinuous loading on cutting edge and flank face are determined by the contact area between tool-tip and substrate material, which depends more on the length of engagement per rotation multiplied by the varies along the cutting edge and rotation number than a simple linear function of workpiece removal rate. Therefore, the development of wear in cutting edge can further exacerbate the heterogeneous distribution of cutting force and thermal, leading to the aggravation of damage.
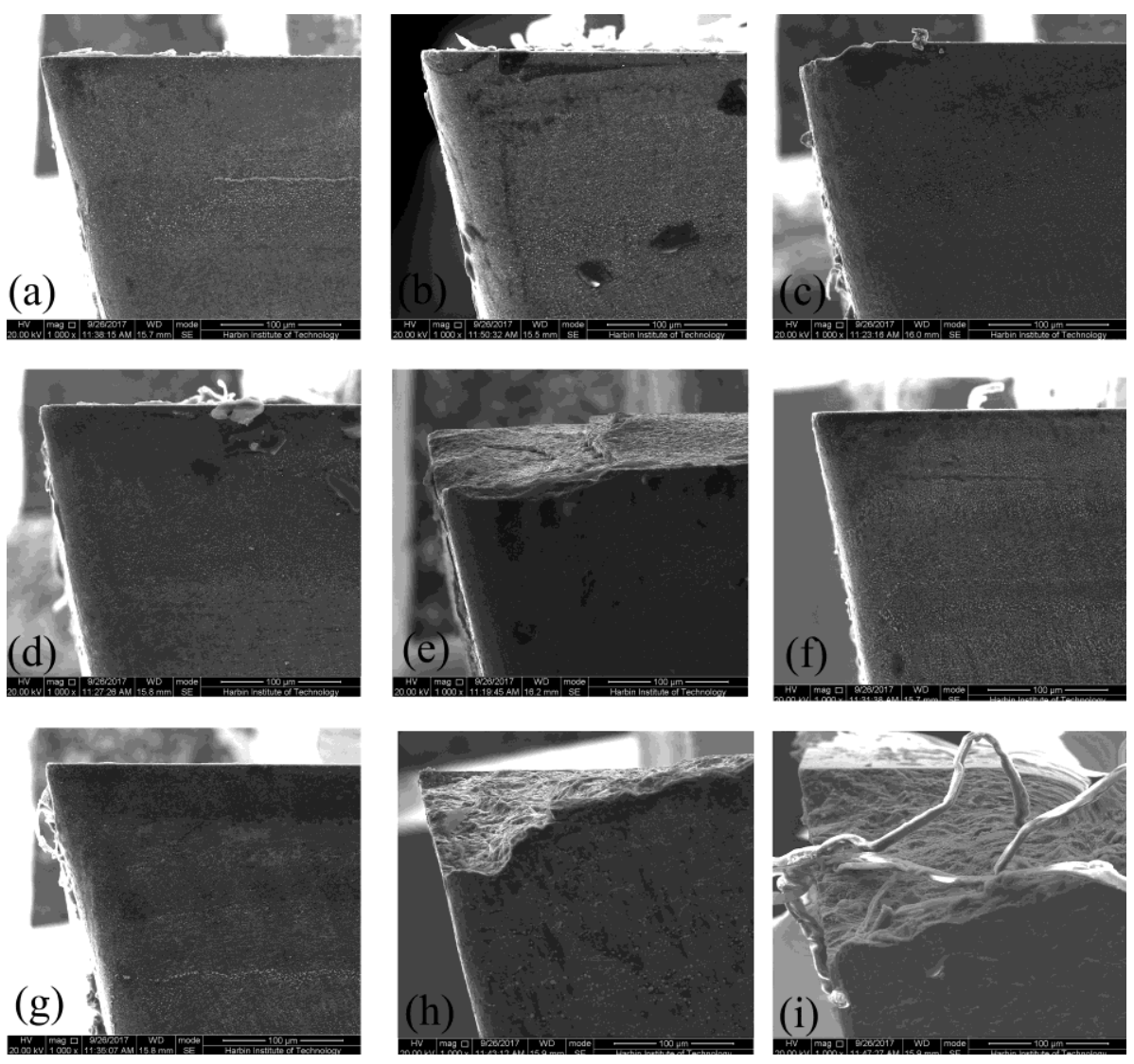

Figure 3. The flank face morphologies of micro-end mills acquired by SEM. The images (a)-(i) represent Test no.1-9.

In micro-milling, tool can form effective negative rake angle because the cutting depth was generally smaller than cutting edge radius. In this way, cutting force in thrust direction became dominant and the damage pattern focused on flank wear, as shown in Figure 3. Instead, if processing titanium alloy Ti-6Al-4V with large diameter tools, the feed force would be primary and the tool failure is mainly caused the wear in the rake face of cutter. In particular, varying rake angle played a critical part in the formation of chips and influenced the shape-structure and 
amplitude of thrust force, which has been proved closely relation with finished surface performance by Bai et al. [20]. In Fig. 3a, the wear area of flank face was small and confined to a tiny scope nearby cutting edge. There was almost no PCD substrate spalling. However, the Fig 3d-3e illustrated the growth of flank wear with rake angle decreased. It can be postulated from above images that the severe adhesion-exfoliative wear could be effectively restrained with the increment of rake angle. The reason is that increased rake angle greatly curbed the shear effect between unprocessed substrate material and tool. It further perfected the morphology and amplitude of thrust force loaded on flank face and minimized the coverage of principal cutting heat. In addition, as tool tip moved through workpiece surface, clearance angle pushed forward an immense influence on forming substrate surface. Not only that, by comparing Fig. 3a and Fig. 3f-3g, although tool showed no sign of significant chipping and spalling features over clearance angle ranges, a certain of diffusive-adhesive phenomena can be found in flank face when clearance angle reached $5^{\circ}$. The Energy Dispersive Spectroscopy (EDS) results of on the worn surface were shown in Fig. 4, indicating that the accumulated material was softening workpiece material. Once the micro-tool was destroyed by fretting fatigue, adhesive abrasion can accelerate the failing process of tool material.

Apart from the micro-end mills of PCD in $10 \mu \mathrm{m}$ diamond grain size, the wear morphologies of PCD tool in $25 \mu \mathrm{m}$ diamond grain size are also illustrated in Fig. 3h-3i. For the latter, the development tendency of flank wear was similar to that of small granularity but with a much larger breaking section. As a result of larger diamond granularity and higher volume fraction of diamond, the PCD tools in Tests no. 8 and no. 9 showed more resistant to titanium alloy abrasion and external impact load but more fragile. Due to the fracture of diamond-diamond and diamond-cobalt bonds, micro-cracks always nucleated and spread at the bonded diamond grain boundaries and cobalt-diamond interfaces. Since the micro-milling process was interrupted with the spindle speed of up to 25000 rpm, mills have to undertake high-frequency impulse load. With the development of crack during tool cut-in and cut-out process, large-scale intergranular fracture features and local abrasion together with scratch were presented on the worn surface, as shown in Fig. 5. Meanwhile, as the cycle of forming and falling off of the adhered titanium alloy Ti-6Al-4V, lots of diamond particles were pulled out periodically. Finally, the visible part of binding cobalt was remained and a large number of micro-pits were exposed in flank face.

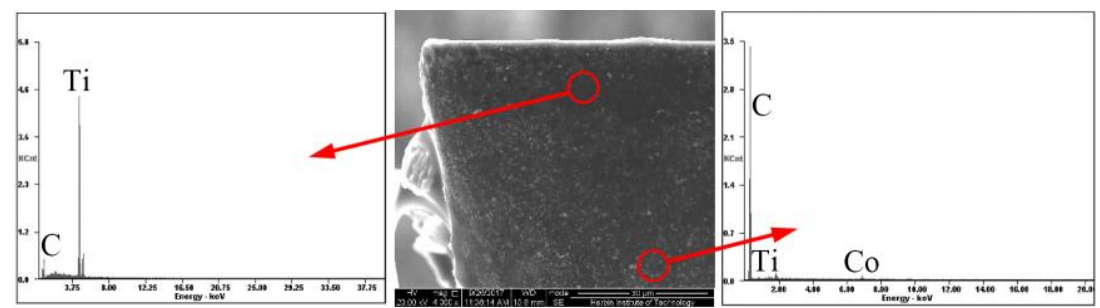

Figure 4. EDS results of worn flank face of tool (g) after milling slot.
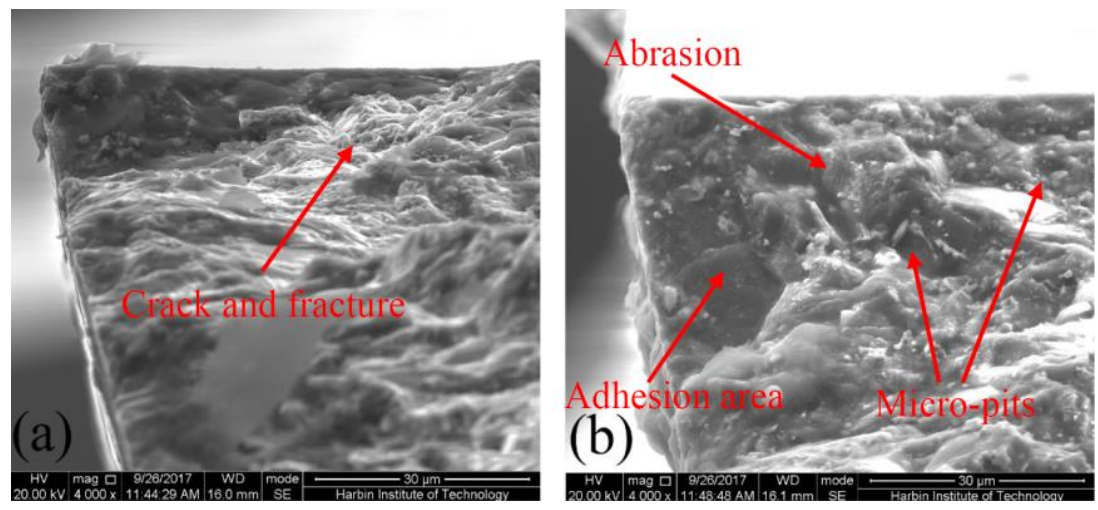

Figure 5. Failure behaviors of PCD tools with large granularity. (a) - Test no. 8; (b) - Test no. 9.

Although PCD tools possess high resistance to crater wear, serious damages were still detected on the rake 
surface of most mills. Fig. 6 showed the worn tool nose and rake face for each milling cutter after machining slots. Actually, the morphologies of tool rake face can offer more immediate local geometrical characteristic of tool structural change. As shown in Fig. 6b-6e and 6g-6i, a mass of chip and a thick build-up layer were found on tool rake surface, which is deemed to one of the main tool failure mechanisms during negative rake angle mode milling process. To some degree, the adhering layer can slow down the development of abrasion wear on their tool surface. However, if adhered titanium alloy was softened and removed, the tool rake face may go through more serious adhesion wear. It indicated that the severe crater wear in the high-worn zone were ascribed to the interaction between attrition behavior and diffusion-adhesion. Particularly, because level of machining parameters remained in micrometer, the external action was more focused on an area of about several square micros around tool tip, which always resulted that the cutting edge was soon blunt and further generated a transition structure, as shown in Fig. 6.
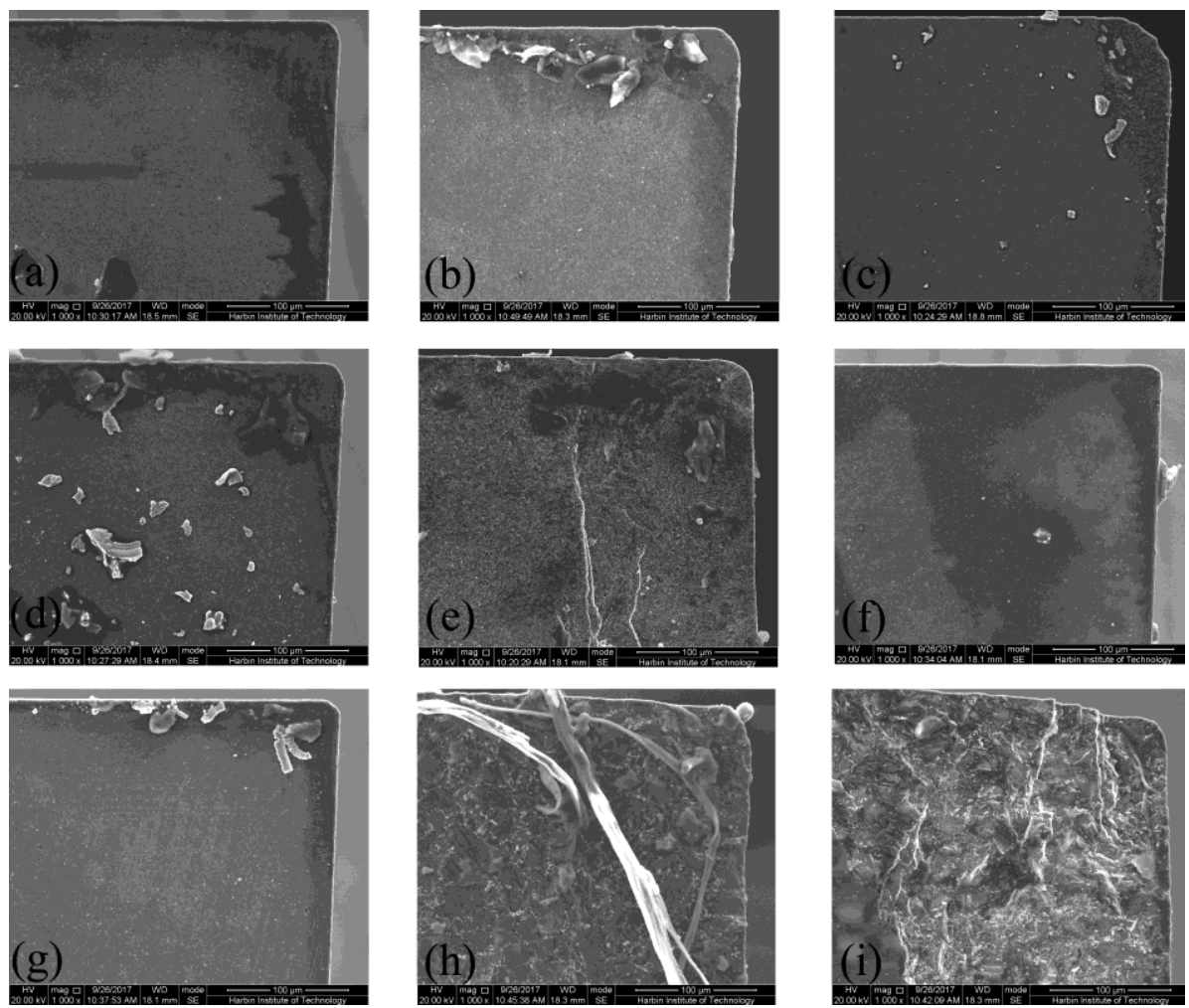

Figure 6. The rake face morphologies of micro-end mills acquired by SEM. The images (a)-(i) represent Test no.1-9.

\subsection{Surface finish of workpiece}

The peaks and grooves can be formed by the successive movements of tools during micro-machining. The friction and wear behavior of tool during milling would lead to the variation of thrust force and the continuous deterioration of processed surface finish. Therefore, the examination of machined surface topography and profile can provide a series of important assessing factors about the cutting performance of PCD tools. The microscopic topographies of micro-slots were presented in Fig. 7. Multiform damages were detected such as micro-crack, workpiece material pull-out, adhered particles, surface tearing and debris of microchips. In general, the shape and distribution of finished surface defects were adopted to reveal the machining quality. As shown in Fig. 7a, the milled surfaces were continuous and uniform without obvious defects and damages and the former mark was covered with latter one gradually, which indicated that the high-quality cutting was achieved. Although few faint feed marks were dimly found in micro-slots, Ulutan et al. [21] considered that adjusting manufacturing conditions based on these defects is intensely difficult in manufacturing titanium alloy Ti-6Al-4V components, and even then, 
a complete elimination is impossible. Furthermore, as the radius of cutting edge developed, scattered flaws, tiny pits and cracks on processed surface became pronounced, as shown in Fig.7b and 7c. It can be explained that the increased radius produced higher gradient of cutting velocity shearing zone in comparison to that in Test no.1. The greater velocity gradient marks a variant strain rate in the vicinity of tool tip, which could result in the nonuniform deformation and even disorder on machined surface. Particularly, since the dwindling tool rake angle increased the squeeze action and further raised the instantaneous temperature between tool and workpiece, the adhered material was presented in the bottom of slot, as shown in Fig. 7e. The plucking action of adhesion particles and their redeposition to surface would result in dragging and tearing defects. Furthermore, the improper clearance angle can exert much stress into the processed surface. Therefore, a mass of apparent feed marks left on groove surface in Fig. 7g. In addition, some damages within fractures and fragments were observed in Fig. 7h and 7i.
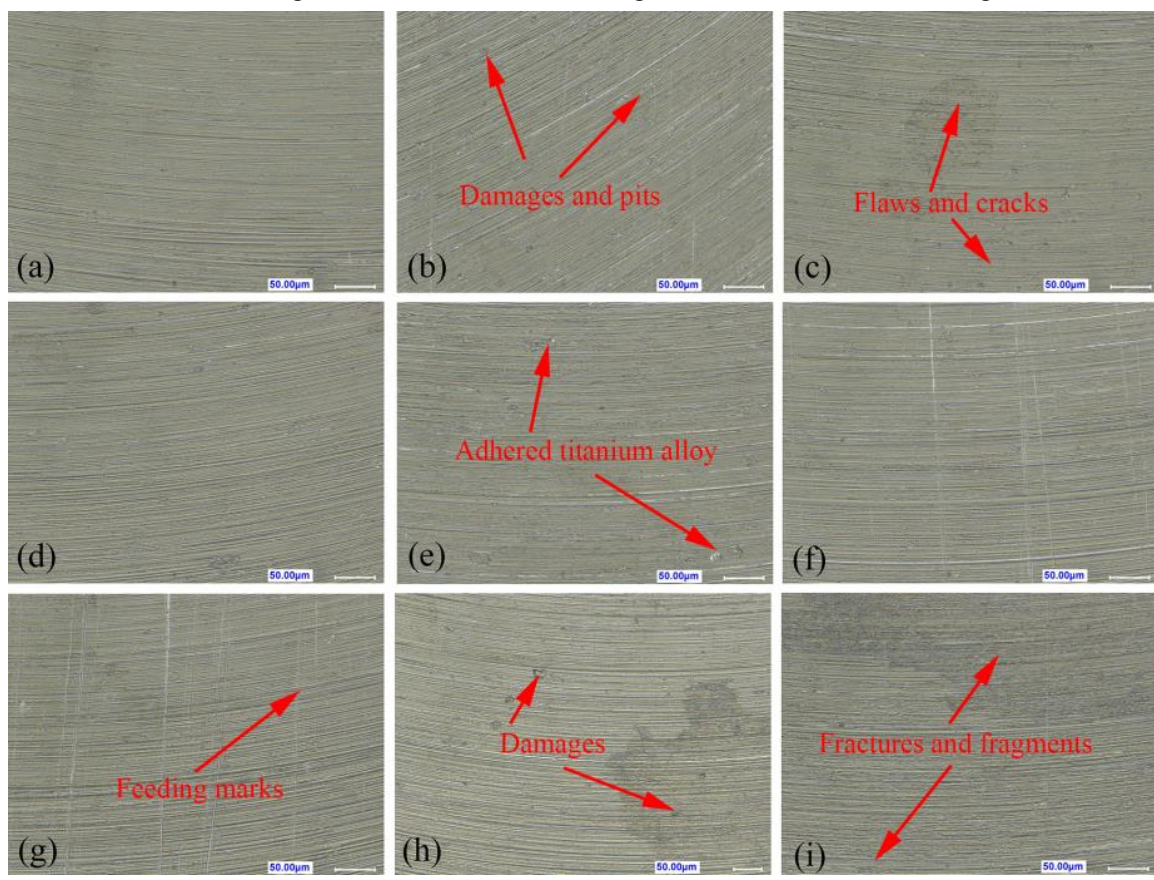

Figure 7. Finished surface topographies processed by different PCD micro-tools. The images (a)-(i) represent Test no.1-9.

For further investigating the dependence of surface precision on tool structural parameters, selected 3D slot surface topographies were shown in Fig. 8. In present study, the optimal machined surface performance was obtained with cutting edge radius $20 \mu \mathrm{m}$ together with rake angle $5^{\circ}$ as well as clearance angle $15^{\circ}$, as shown in Fig. 8a. In this way, the milling paths were clarity and stabilization without obvious micro-crack or tearing chipping. Furthermore, the morphology characteristic indicated that the larger tool cutting edge radius or smaller rake angle as well as clearance angle enabled more seriously surface damages and hence boosting partial stable micro-milling mode and unsteady machining process. Note that although partial stable can occasionally generate irreversible surface defects, only bits of burrs and micro-damages was found in Fig. 8d. On the contrary, the unsteady cutting process not only formed rugged cutting marks but formed a large number of chaotic burrs as well as micro-cracks, as shown in Fig. 8b. In addition, Fig. 8c presented the significant waviness of machining paths rather than slits and pits. The reason may be that the thermal softening and compressive stress in finished surface contributed to clearing out surface flaws and facilitating titanium alloy substrate to reconstruct itself. 

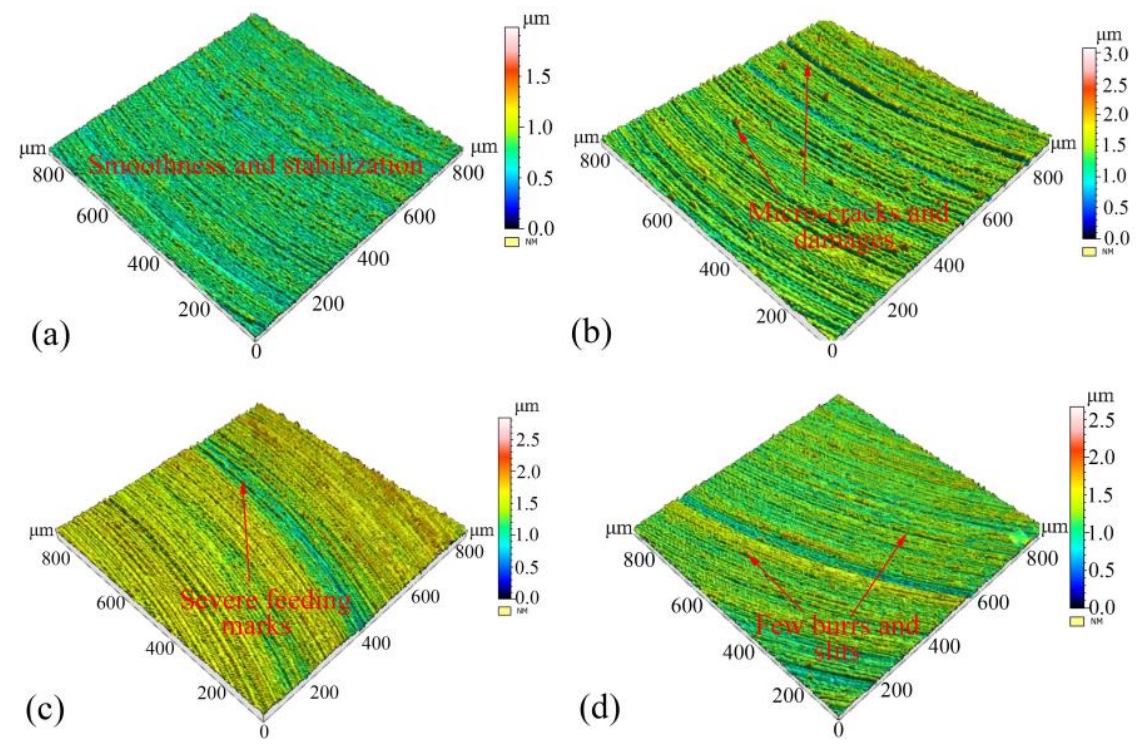

Figure 8. Selected cutting surface three-dimensional topographies. The images (a)-(d) represent Test no.1, 3, 5, 7.

In this work, the arithmetic surface roughness Ra, which could acquire the information of machined surface geometrical characteristic, was used to quantitatively investigate the inner influence of tool geometry on slots finish. For every micro-slot, three random positions along cross section were detected and the mathematic average values were calculated in Table 1. Particularly, all of initial data was presented in Table 3 (Appendix A). In this work, all the obtained surface finish was lower than $200 \mathrm{~nm}$. Particularly, the $75 \mathrm{~nm}$ surface roughness Ra, which is better than most previously reported value on titanium alloy Ti-6Al-4V, was achieved in Test no.1 [22]. Aslantas et al. [23] reported an investigation on micro-milling titanium alloy Ti-6Al-4V by $0.5 \mathrm{~mm}$ nano-crystalline diamond coated tools and the surface finish values acquired were within the scope of $0.2 \mu \mathrm{m}$ and $1 \mu \mathrm{m}$. Furthermore, the evolution rule of surface precision with tool geometrical transformation were plotted in Fig. 9. As shown in Fig. 9a, the invariable extrinsic parameters were configured: $5^{\circ}$ for rake angle and $15^{\circ}$ for clearance angle. The curve indicated that cutting edge has negative effect to machined surface quality, i.e. the ever-increasing of cutting edge radius can deteriorate surface finish. As represented in fig. $9 \mathrm{~b}$, the rake angle increased from $1^{\circ}$ to $5^{\circ}$, while the remaining arguments still kept the same. Rake angle showed a notable influence on finished surface precision. A maximum $47.2 \%$ promotion for surface accuracy can be found. Fig. 9c demonstrated how the micro-slot bottom roughness changes when the clearance angle varies. As expected, the surface accuracy is apt to improve with the increment of clearance angle. By analyzing the roughness value in Table 1, the changes of tool structure could gain a worst surface performance, $\mathrm{Ra}=0.142 \mu \mathrm{m}$. However, the difference of varying diamond granularity can achieve a maximum roughness value of $\mathrm{Ra}=0.2 \mu \mathrm{m}$.
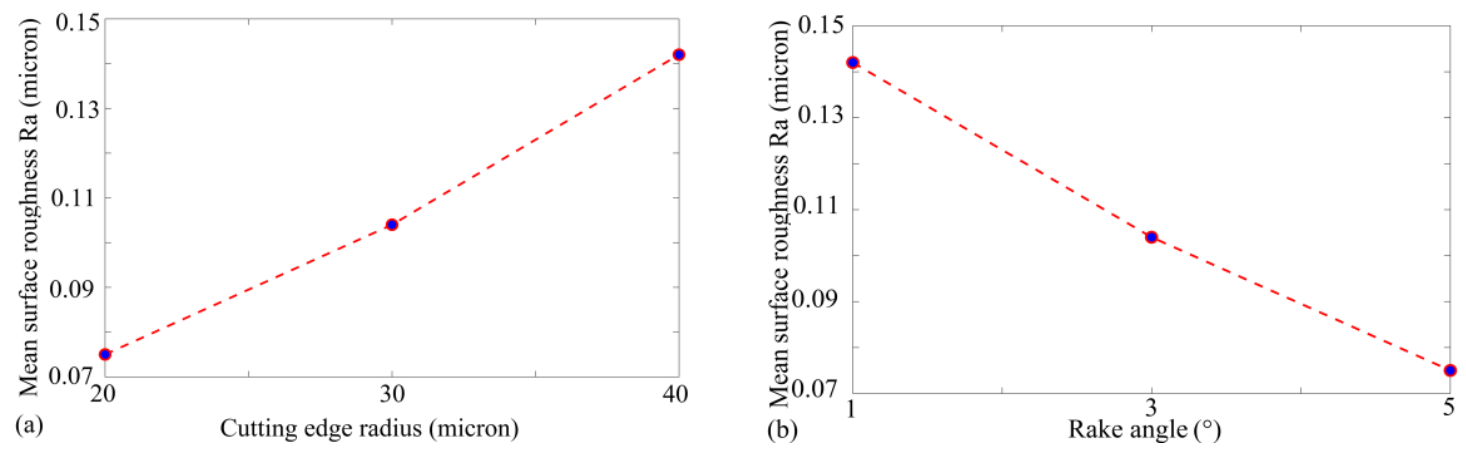


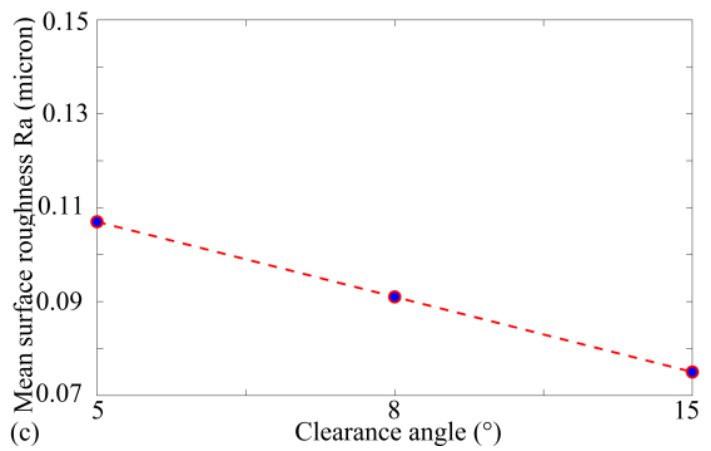

Figure 9. The influence plots of single factor on surface roughness: (a) - cutting edge radius; (b) - rake angle; (c) - clearance angle.

\subsection{Subsurface microstructure of workpiece}

Bermingham et al. [24] indicated that titanium alloy Ti-6Al-4V consists of equal-axis alpha phase grains and a small amount of intergranular beta-titanium grains. By investigating the effect of plastic strain imparted on titanium alloy Ti-834 and Ti-6Al-4V substrate in milling operation, Thomas et al. [25] asserted that the discrete dislocation nucleation and propagation in alpha grains are a fundamental component of substrate defects layer. Particularly, because of the increasing Al content, Fernandez-Zelaia et al. [26] reported that the cutting numerical simulation could ignore deformation twinning. Two-dimensional representative polycrystal model was established to reveal the subsurface microstructure transformation process, where the dimension of hexagonal close-packed grain is $3.4 \mu \mathrm{m} \times 2.95 \mu \mathrm{m}$. Through a structured approach, the subsurface deformation in the model can be classified into a series of independent slip system, as shown in Fig.10. Other part detailed constants were listed in Table 2. Moreover, special finite element algorithms were programmed into the package for examining the dislocation behavior in machining. Linear plane strain thermally coupled quadrilateral element with reduced integration was used in coupled thermo-mechanical solution under orthogonal cutting conditions. Tool enter angle and inclination angle were fixed at $90^{\circ}$ and $0^{\circ}$. The cutting depth and cutting speed were set as $10 \mathrm{~m} / \mathrm{s}$ and $1 \mu \mathrm{m}$, respectively.

Table 2. Material coefficient of Titanium alloy Ti-6Al-4V

\begin{tabular}{c|c|c|c|c|c|c|c|c}
\hline & Vacancy & diffusion & drag & P-N & Nucleation & pre-existing & dislocation & obstacle \\
& energy & constant & coefficient & force & stress & dislocation & sources & sources \\
& $\left(\Delta E_{\mathrm{sd}}\right)$ & $\left(D_{0}\right)$ & $\left(B_{\mathrm{g}}\right)$ & $\left(f_{0}\right)$ & $\left(\tau_{\text {nuc }}\right)$ & density & density & density \\
\hline Value & $2.509 \mathrm{eV}$ & $0.015 \mathrm{~cm}^{2} / \mathrm{s}$ & $1.4 \times 10^{-4} \mathrm{~Pa} \mathrm{~s}$ & $0.02 \mathrm{MPa}$ & $0.8 \mathrm{GPa}$ & $6.25 \times 10^{12} \mathrm{~m}^{-2}$ & $4.2 \times 10^{13} \mathrm{~m}^{-2}$ & $2.1 \times 10^{13} \mathrm{~m}^{-2}$ \\
\hline
\end{tabular}

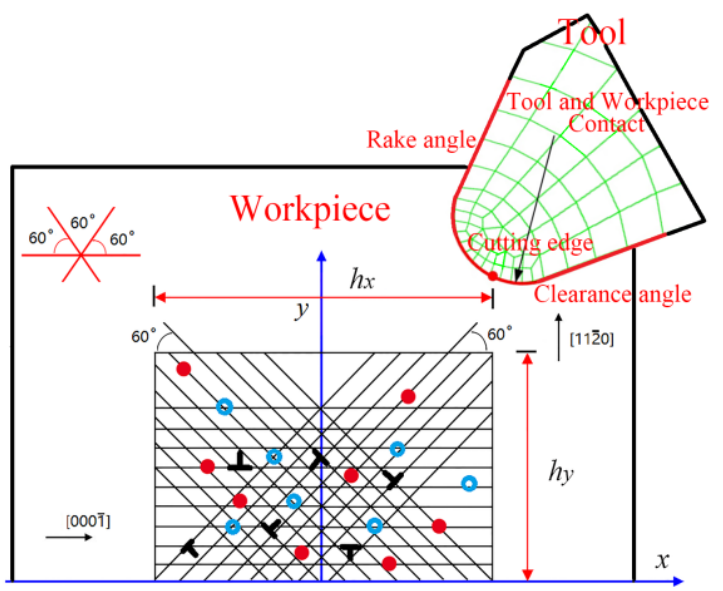

Figure 10. Mesoscale orthogonal cutting simulation model, which is composed of the pre-existing dislocations, glide system, grain 
boundary, F-R sources (solid circle) and obstacle sources. The radius of cutting edge is $0.25 \mu \mathrm{m}$, the rake angle is $5^{\circ}$ and the clearance angle is $15^{\circ}$.

The microstructural features of subsurface defects layer generated with different mills were arrayed in Fig. 11. As illustrated in Fig. 11a and 11b, a small amount of dislocations evolved at the bottom of regional shear field when the radius of cutting edge much below the depth of cut. Nevertheless, as it approached until closed to the uncut chip thickness, the dominant thrust force would provide substantially higher quantity levels for subsurface damages in Fig. 11c and 11d. Furthermore, although different amounts of subsurface defects were formed, all of substrates shared a series of morphological characteristics i.e. discrete dislocation configuration, parallel glide lines and intertwining dislocation bands. In addition, based on the measurement investigations of the subsurface damages layer thickness, the change of subsurface depth with cutting edge radius was acquired. When the cutting distance reached $10 \mu \mathrm{m}$, the damages layer was thin and stable in Fig. 11a. However, massive power dissipation induced by rising cutting edge radius produced a considerably negative impact on subsurface. A side-effect is that it promoted the multiplication rate and boosted the locomotivity and movement velocity of dislocation. Therefore, the activity dislocations existed in deep surface layer evolved downwards until the bottom was reached.
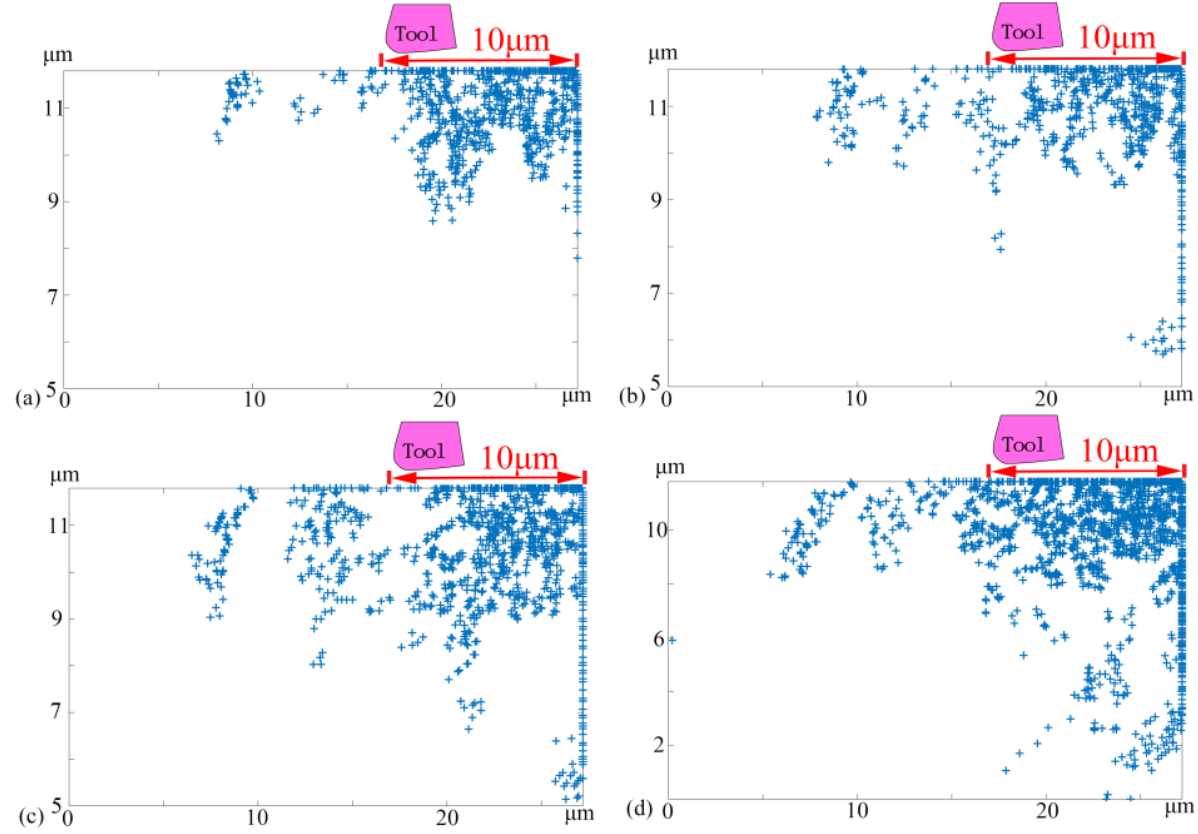

Figure 11. Subsurface microstructural transformation with various tool cutting edge radii. (a) $0 \mu \mathrm{m}$; (b) $0.25 \mu \mathrm{m}$; (c) $0.5 \mu \mathrm{m}$; (d) $1 \mu \mathrm{m}$.

According to previous experiments, identical geometrical parameters of tool were used to reveal the effect of rake angle on substrate microstructure transformation. In the inception phase, discontinuous loading and heat stress induced that a handful of pre-existing dislocations cannot timely response to external events. Therefore, workpiece subsurface has to continue generating dislocation dipoles to afford plasticity deformation. Fig. 12 showed that the increased rake angle contributed to inhibiting crystal distortion and improving subsurface qualities at the moment of cutting-in. In addition, large tool rake angle could drop off the number and scale of defects as well as reduce the subsurface damages layer thickness significantly. For instance, when the rake angle enhanced from $1^{\circ}$ to $10^{\circ}$, a nearly $40.6 \%$ decline can be obtained. It implies that small rake angle could produce larger region of heat dissipation in subsurface substrate, which leaves persistent slip band dominating the near-surface damages layer and leads to heat-activated dislocation nucleation in deep-surface damages layer.

Figure 13 presented the instantaneous subsurface microstructural features with various clearance angles when cutting distance is $10 \mu \mathrm{m}$. By analyzing and comparing, it is easy to conclude that the $0^{\circ}$ clearance angle brought great influence upon workpiece substrate. One of the causes for greater subsurface damages layer thickness is that 
the horizontal flank surface induced that the titanium alloy materials have to withstand the prolonged hydrostatic pressure and friction action, which could further result in the secondary nucleation of remnant F-R dislocation sources as well as newly formed junction or interlocking. Particularly, as tool clearance angle increased, such terrible feature could be immediately removed, as shown in Fig. 13b. Note that, with the $5^{\circ}$ of tool clearance angle reached, the subsequent augment of clearance angle hardly made a quite difference for subsurface features in Fig. $13 \mathrm{c}$ and $13 \mathrm{~d}$. It is shown that the excessive clearance is not conducive to forming better surface finish.

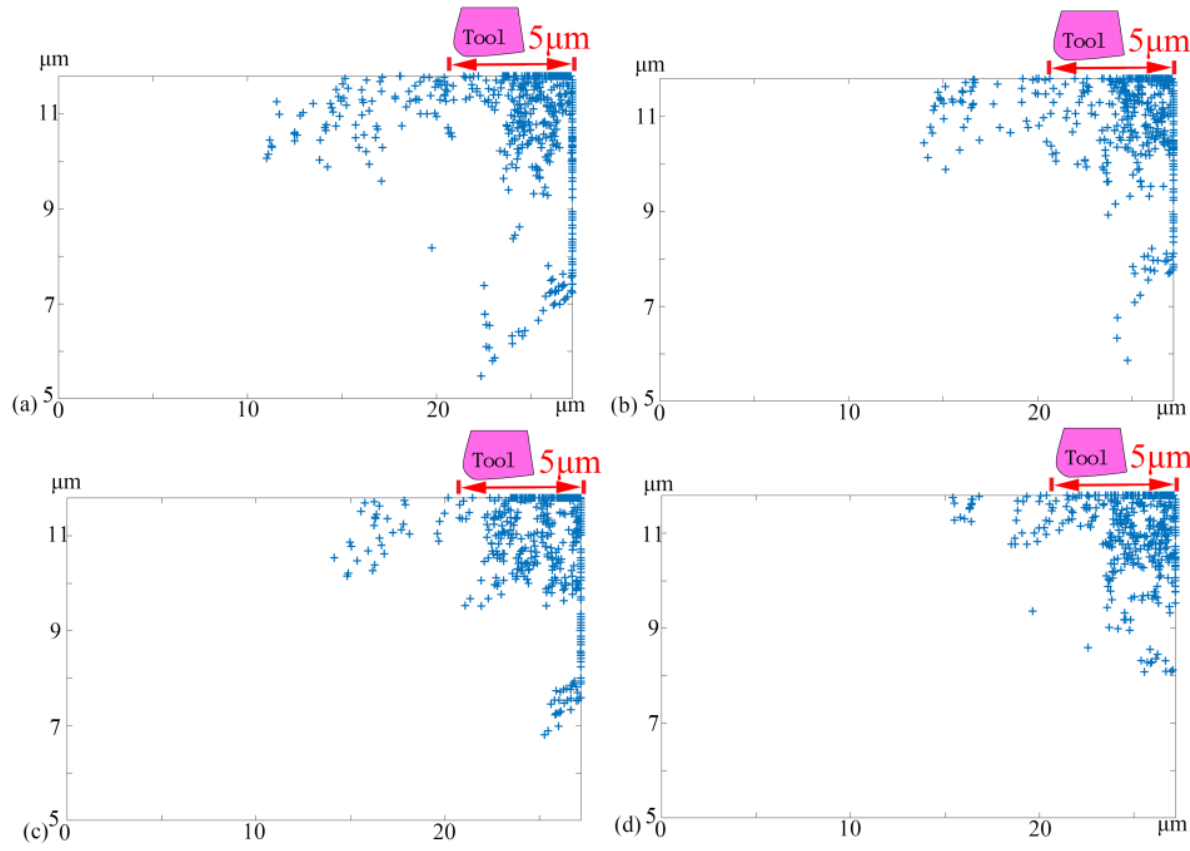

Figure 12. Subsurface microstructural transformation with various tool rake angles. (a) $1^{\circ}$; (b) $3^{\circ}$; (c) $5^{\circ}$; (d) $10^{\circ}$.
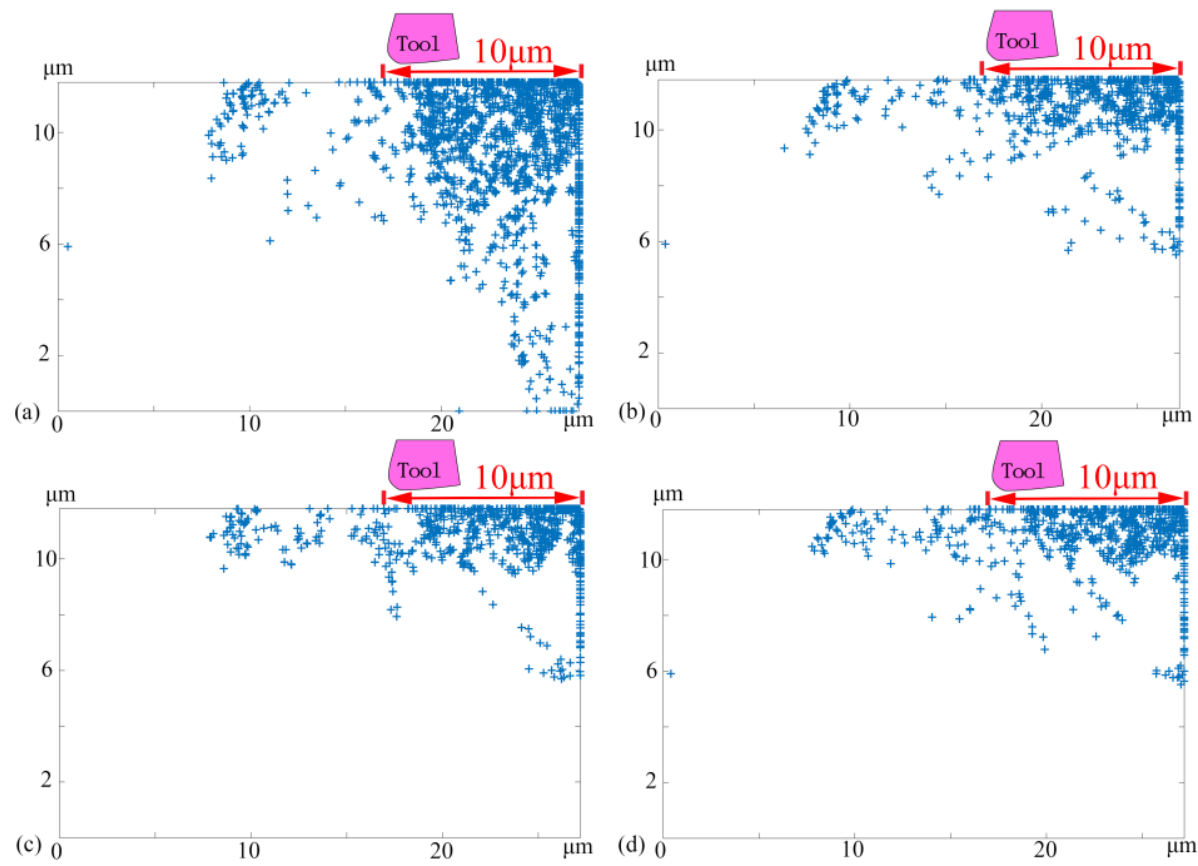

Figure 13. Subsurface microstructural transformation with various clearance angles. (a) $0^{\circ}$; (b) $5^{\circ}$; (c) $8^{\circ}$; (d) $15^{\circ}$. 


\section{Conclusions}

In this work, micro-machining titanium alloy experiments were conducted by various PCD micro-end mills. Fundamental characteristics of the machining process, including the wear of cutter, surface topography, roughness and subsurface damages microstructure, were examined and discussed in details. The following conclusions can be highlighted:

1. The results obtained indicated that the major wear features of PCD tools were tool nose wear, flank wear and rake wear. In general, tool nose wear was promoted with the increment of cutting edge radius. Increased rake angle significantly curbed the shear and friction action between unprocessed substrate and tool-tip, which eventually restrained the adhesion-exfoliative wearing of flank face.

2. Large-scale intergranular fracture features and local abrasion together with scratch were found on the surface of PCD within $25 \mu \mathrm{m}$ diamond grain size. Furthermore, as the cycle of forming and falling off of adhesive titanium alloy, a large number of diamond particles were pulled out periodically.

3. Influence of tool structure on machined surface performance was investigated quantitatively and qualitatively. The surface roughness Ra is critically influenced by tool geometrical parameters. Mean surface finish of $75 \mathrm{~nm}$ on the bottom of slots better than most previously reported value on titanium alloy Ti-6Al-4V was achieved by selecting reasonable parameters.

4. An DD-based multiscale coupling model was used for providing detailed insight into subsurface damages layer microstructure. Plenty of subsurface defects consisted of dislocation configuration, parallel dislocation lines and persistent slip bands can be found after cutting.

5. Small tool cutting edge radius together with large rake angle and clearance angle were helpful to reduce defect quantity and decrease the thickness of subsurface damages layer.

\section{Acknowledgments}

This research was supported by National Natural Science Foundation of China (Grant No. 51575138), the State Key Program of National Natural Science Foundation of China (Grant No. 51535003) and the scholarship from China Scholarship Council (Grant No. 201706120138). The authors thank Shanghai Naisi Precision Tool Company for providing the PCD tool.

Appendix A: Initial measured results

Table 3. Machined surface roughness results at different conditions

\begin{tabular}{cccccccccc}
\hline Responses & \multicolumn{8}{c}{ Surface roughness Ra (nm) } \\
\hline Exp.no & 1 & 2 & 3 & 4 & 5 & 6 & 7 & 8 & 9 \\
\hline Test.1 & 70.66 & 121.38 & 121.97 & 88.68 & 151.06 & 77.80 & 115.76 & 162.97 & 160.78 \\
\hline Test.2 & 63.28 & 104.19 & 147.05 & 112.11 & 121.43 & 95.59 & 93.27 & 169.32 & 211.75 \\
\hline Test.3 & 91.15 & 103.87 & 137.21 & 112.15 & 155.59 & 99.81 & 112.09 & 163.08 & 228.66 \\
\hline
\end{tabular}

\section{References}

[1]. F. Ducobu, E. Riviere-Lorphevre, E. Filippi, Numerical contribution to the comprehension of saw-toothed Ti6Al4V chip formation in orthogonal cutting, Int. J. Mech. Sci. 81 (2014) 77-87.

[2]. G.X. Li, S. Yi, S.J. Sun, et al., Wear mechanisms and performance of abrasively ground polycrystalline diamond tools of different diamond grains in machining titanium alloy, J. Manuf. Process. 29 (2017) 320-331. 
[3]. A.K.M. Amin, A. Ismail, M.K. Khairusshima, Effectiveness of uncoated WC-Co and PCD inserts in end milling of titanium alloy Ti-6Al-4V, J. Mater. Process. Tech. 192-193 (2007) 147-158.

[4]. X. Ding, W.Y.H. Liew, X.D. Liu, Evaluation of machining performance of MMC with PCBN and PCD tools, Wear. 259 (2005) 1225-1234.

[5]. J.X. Bai, Q.S. Bai, C. Hu, et al., Research on the ductile-mode machining of monocrystalline silicon using polycrystalline diamond (PCD) tools, Int. J. Adv. Manuf. Tech. (2017) 1-9.

[6]. W.F. Salesa, J. Schoop, I.S. Jawahir, Tribological behavior of PCD tools during superfinishing turning of the Ti6Al4V alloy using cryogenic, hybrid and flood as lubri-coolant environments, Tribol. Int. 114 (2017) 109-120.

[7]. A.H. Li, J. Zhao, D. Wang, Failure mechanisms of a PCD tool in high-speed face milling of Ti-6Al-4 V alloy, Int. J. Adv. Manuf. Technol. 67 (2013) 1959-1966.

[8]. R.B. Silva, A.R. Machadoa, E.O. Ezugwub, et al., Tool life and wear mechanisms in high speed machining of Ti-6Al-4V alloy with PCD tools under various coolant pressures, J. Mater. Process. Tech. 213 (2013) 1459-1464.

[9]. S.A. Abbasi, P.F. Feng, Y. Ma, et al., Influence of microstructure and hardness on machinability of heat-treated titanium alloy Ti-6Al-4V in end milling with polycrystalline diamond tools, Int. J. Adv. Manuf. Techno. 86 (2016) 1393-1405.

[10]. Y.S. Su, Z. Li, L. Li, et al., Cutting performance of micro-textured polycrystalline diamond tool in dry cutting, J. Manuf. Process. 27 (2017) 1-7.

[11]. G.X. Li, M.Z. Rahim, S.L. Ding, et al., Performance and wear analysis of polycrystalline diamond (PCD) tools manufactured with different methods in turning titanium alloy Ti-6Al-4V, Int. J. Manuf. Technol. 85 (2016) $825-841$.

[12]. Q.L. Wang, Q.S. Bai, J.X. Chen, et al., Subsurface defects structural evolution in nano-cutting of single crystal copper, Appl. Surf. Sci. 344(2015) 38-46.

[13]. C. H. Che-Haron, Tool life and surface integrity in turning titanium alloy, J. Mater. Process. Tech 118 (2001) 231-237.

[14]. J.X. Bai, Q.S. Bai, Z. Tong, Evolution of surface grain structure and mechanical properties in orthogonal cutting of titanium alloy, J. Mater. Res. 31 (2016) 3919-3929.

[15]. J.X. Bai, Q.S. Bai, Z. Tong, et al., The influence of cutting parameters on the defect structure of subsurface in orthogonal cutting of titanium alloy, J. Mater. Res. (2017) 1-13.

[16]. J.X. Bai, Q.S. Bai, Z. Tong, Dislocation dynamics-based modeling and simulations of subsurface damages microstructure of orthogonal cutting of titanium alloy, Micromachines 8 (2017) 309.

[17]. M.S. Huang, Z.H. Li, Coupled DDD-FEM modeling on the mechanical behavior of microlayered metallic multilayer film at elevated temperature, J. Mech. Phys. Solids. 85 (2015) 74-97.

[18]. K.M. Davoudi, L. Nicola, J.J. Vlassak, Dislocations climb in two-dimensional discrete dislocation dynamics, J. Appl. Phys. 111 (2012) 103522.

[19]. A.A. Benzerga, Y. Brechet, A. Needleman, et al., Incorporating three-dimensional mechanisms into two-dimensional dislocation dynamics, Model. Simul. Mater. Sci. Eng. 12 (2004) 159-196.

[20]. J.X. Bai, Q.S. Bai, Z. Tong, Multiscale Analyses of Surface Failure Mechanism of Single-Crystal Silicon during Micro-Milling Process, Materials. 10 (2017) 1424.

[21]. D. Ulutan, T. Ozel, Machining induced surface integrity in titanium and nickel alloys: A review, Int. J. Mach. Tool. Manu. 51 (2011) 250-280.

[22]. D. Yang, Z.Q. Liu, Surface topography analysis and cutting parameters optimization for peripheral milling titanium alloy Ti-6Al-4V, Int. J. Refract. Met. H. 51 (2015) 192-200.

[23]. K. Aslantas, H.E. Hopa, M. Percin, et al. Cutting performance of nano-crystalline diamond (NCD) coating in micro-milling of Ti6Al4V alloy, Precis. Eng. 45 (2016) 55-66. 
[24]. M.J. Bermingham, S.D. McDonald, M.S. Dargusch, et al., Grain-refinement mechanisms in titanium alloys. J. Mater. Res. 23 (2008) 97-104.

[25]. M. Thomas, S. Turnerb, M. Jackson, Microstructural damage during high-speed milling of titanium alloys, Scripta. Mater. 62 (2010) 250-253.

[26]. P. Fernandez-Zelaia, S. Melkote, T. Marusich, et al., A microstructure sensitive grain boundary sliding and slip based constitutive model for machining of Ti-6Al-4V. Mech. Mater. 109(2017) 67-81. 